\title{
Organizational resilience: a capability-based conceptualization
}

\author{
Stephanie Duchek ${ }^{1}$ (D)
}

Received: 29 May 2017/Accepted: 4 January 2019/Published online: 14 January 2019

(C) The Author(s) 2019

\begin{abstract}
In highly volatile and uncertain times, organizations need to develop a resilience capacity which enables them to cope effectively with unexpected events, bounce back from crises, and even foster future success. Although academic interest in organizational resilience has steadily grown in recent years, there is little consensus about what resilience actually means and how it is composed. More knowledge is particularly needed about organizational capabilities that constitute resilience, as well as conditions for their development. This paper aims to make a contribution to this heterogeneous research field by deepening the understanding of the complex and embedded construct of organizational resilience. We conceptualize resilience as a meta-capability and decompose the construct into its individual parts. Inspired by process-based studies, we suggest three successive resilience stages (anticipation, coping, and adaptation) and give an overview of underlying capabilities that together form organizational resilience. Based on this outline, we discuss relationships and interactions of the different resilience stages as well as main antecedents and drivers. We formulate propositions that can act as a foundation for future empirical work.
\end{abstract}

Keywords Organizational resilience $\cdot$ Resilience capacity $\cdot$ Resilience process $\cdot$ Resilience capabilities

JEL Classification M10 - L20

Stephanie Duchek

stephanie.duchek@tu-dresden.de

1 Faculty of Business and Economics, Technische Universität Dresden, 01062 Dresden, Germany 


\section{Introduction}

In highly volatile and uncertain times, organizations are frequently confronted with unexpected events such as natural disasters, terrorist attacks or technical malfunctions. ${ }^{1}$ In the literature, the abstract notion of the unexpected is specified using different concepts: some authors talk about 'rare events' (Marcus and Nichols 1999; Lampel et al. 2009; Starbuck 2009), while others call it 'surprises' (Lampel and Shapira 2001; Bechky and Okhuysen 2011), 'catastrophes' (Weick and Roberts 1993; Majchrzak et al. 2007), or 'crises' (Weick 1988; Pearson and Clair 1998; Rerup 2009). The unexpected may arise within or outside of the organization and can refer to different dimensions or aspects: e.g., the kind of event, time, and place of its occurrence, frequency, and duration of the event. Furthermore, the importance and magnitude of its effects on the organization can be surprising.

To survive in uncertain environments and to foster future success, organizations must be able to handle all of these manifestations of the unexpected. Firms need to develop a resilience capacity which enables them to adequately react to unexpected events and to capitalize on events that could potentially threaten an organization's survival (Lengnick-Hall et al. 2011). In this function, resilience differs from related constructs such as flexibility, agility or robustness. Although flexibility as the ability to rapidly adjust to environmental changes (Golden and Powell 2000), and agility as the "ability quickly to recognize opportunities, change direction, and avoid collisions" (McCann 2004, p. 47) have some elements in common with resilience, the specific emphases of the constructs tend to be different. While flexibility and agility are necessary to deal with daily problems and changes, resilience is an important success factor in dealing with unexpected threats and crises (LengnickHall et al. 2011). Furthermore, resilience includes an adaptation aspect (Madni and Jackson 2009) and allows firms to come out of a crisis stronger than before. This characteristic distinguishes resilience from robustness, which is defined as the ability of a system to maintain functions despite disruptions (Kitano 2004).

Although the academic interest in organizational resilience has steadily grown in recent years, the conceptualization of the complex construct is still in its infancy. There is no consensus about what resilience means and which elements it contains. Most studies just point to organizational characteristics, resources, or processes that seem to be significant for resilience (e.g., Weick 1993; Kendra and Wachtendorf 2003; Gittell et al. 2006). This means that resilience is simply treated as an outcome-when organizations perform well during crisis or bounce back from interruptions (e.g., Horne and Orr 1998). But this falls short: it remains unclear what resilient organizations actually do and how organizational resilience may be achieved in practice (Boin and van Eeten 2013; Duit 2016). It is the aim of our paper to make a contribution to this promising research field.

We conceptualize resilience as a meta-capability and decompose the construct into its individual parts. Building on process-based resilience research, we define

\footnotetext{
1 This paper focuses on unexpected events with a potential for high consequence (Pearson and Clair 1998). This means that the events may hinder or prevent organizational functioning and, thereby, threaten the achievement of strategic goals. Crisis serves as an umbrella term for these kinds of unexpected events (Hermann 1963; Smart and Vertinsky 1984; Herbane 2010).
} 
three successive resilience stages (anticipation, coping, and adaptation) and assign important organizational capabilities to each of these stages. To provide deeper insight into the functioning of those capabilities, we merge findings from different research areas (e.g., business continuity management, crisis management, innovation management). Beyond that, we highlight important relationships and interactions of the different resilience stages as well as main antecedents and drivers. The result of this process is "an explicit, informed, conceptual framework" (Lynham 2002 , p. 232) of organizational resilience that fosters a comprehensive understanding of the resilience phenomenon as well as underlying dynamics (see Meredith 1993; Jabareen 2009; Burnard and Bhamra 2011). This framework can be seen as a first step towards a resilience theory. It introduces key concepts, organizes the heterogeneous research field, and explains theoretical relationships. Furthermore, the framework can serve as a basis for the operationalization of the complex resilience construct and for future empirical research.

This paper is structured as follows: in section two, we provide an overview of previous research on organizational resilience and identify promising approaches for a contemporary and future-oriented conceptualization. In section three, we develop our conceptual framework of organizational resilience and structure the resilience literature as well as the literature of related areas according to the framework. We discuss relationships and interactions of resilience capabilities, highlight main antecedents and drivers, and formulate propositions that can be used as a starting point for future empirical studies. Finally, in section four, we summarize our findings and give general implications for further research.

\section{Previous research on organizational resilience}

While the resilience concept has a long tradition in some disciplines (especially in psychology), it is relatively new in business and management research. Linnenluecke's (2017) review shows that research in this field is fragmented across several research streams (organizational responses to external threats, organizational reliability, employee strengths, the adaptability of business models, and design principles that reduce supply chain vulnerabilities). All these research streams have developed their own definitions, conceptualizations, and measures of resilience. The focus of this paper is directed towards resilience as an organizational construct and includes findings from different research streams to create a coherent and comprehensive picture of the complex construct.

\subsection{Definitions of organizational resilience}

Since the beginning of the 21 st century, research on organizational resilience has developed tremendously (a Google Scholar search shows 98 results for 1985-2000 and 3270 results for 2001-2015). However, there is no consistent understanding of the construct. Organizational resilience comprises numerous and divergent themes. It can be seen as an umbrella construct- " a broad concept or idea used loosely to encompass and account for a set of diverse phenomena" (Hirsch and Levin 1999, 
p. 200). Researchers often use their own label for the concept (e.g., organizational resilience, resilience capacity, resilience potential, and resilient organization), and there are numerous independent, ambiguous, and partly inconsistent definitions of the construct. Table 1 gives an overview of important resilience definitions in the organizational context from 1998 to 2015 and displays their main emphases.

Generally, three main perspectives on organizational resilience can be distinguished. The first group of scholars understands resilience as an organization's

Table 1 Organizational resilience: perspectives and example definitions

\begin{tabular}{|c|c|c|c|c|}
\hline $\begin{array}{l}\text { Resilience is } \\
\text { understood } \\
\text { as... }\end{array}$ & Author(s) & Year & $\begin{array}{l}\text { Resilience } \\
\text { concept }\end{array}$ & Definition \\
\hline \multirow[t]{3}{*}{$\begin{array}{l}\text { Resistance } \\
\text { and } \\
\text { recovery }\end{array}$} & Horne and Orr & 1998 & $\begin{array}{l}\text { Organizational } \\
\text { resilience }\end{array}$ & $\begin{array}{l}\text { "Resilience is a fundamental quality }(\ldots) \text { to } \\
\text { respond productively to significant change } \\
\text { that disrupts the expected pattern of event } \\
\text { without engaging in an extended period of } \\
\text { regressive behavior" (p. 31) }\end{array}$ \\
\hline & $\begin{array}{l}\text { Linnenluecke } \\
\text { et al. }\end{array}$ & 2012 & $\begin{array}{l}\text { Organizational } \\
\text { resilience }\end{array}$ & $\begin{array}{l}\text { Resilience is the "organizational capacity to } \\
\text { absorb the impact and recover from the } \\
\text { actual occurrence of an extreme weather } \\
\text { event" (p. 18) }\end{array}$ \\
\hline & $\begin{array}{l}\text { Boin and } \\
\text { Eeten }\end{array}$ & 2013 & $\begin{array}{l}\text { Recovery } \\
\text { resilience }\end{array}$ & $\begin{array}{l}\text { Recovery resilience means "bouncing back to } \\
\text { a state of normalcy" (p. 431) }\end{array}$ \\
\hline \multirow[t]{3}{*}{ Adaptation } & $\begin{array}{l}\text { Reinmoeller } \\
\text { and van } \\
\text { Baardwijk }\end{array}$ & 2005 & $\begin{array}{l}\text { Resilient } \\
\text { companies }\end{array}$ & $\begin{array}{l}\text { Resilience is "the capability to self-renew } \\
\text { over time through innovation" (p. 61) }\end{array}$ \\
\hline & $\begin{array}{l}\text { Vogus and } \\
\text { Sutcliffe }\end{array}$ & 2007 & $\begin{array}{l}\text { Organizational } \\
\text { resilience }\end{array}$ & $\begin{array}{l}\text { Resilience is "the maintenance of positive } \\
\text { adjustment under challenging conditions } \\
\text { such that the organization emerges from } \\
\text { those conditions strengthened and more } \\
\text { resourceful" (p. 3418) }\end{array}$ \\
\hline & $\begin{array}{l}\text { Lengnick- } \\
\text { Hall et al. }\end{array}$ & 2011 & $\begin{array}{l}\text { Organizational } \\
\text { resilience } \\
\text { capacity }\end{array}$ & $\begin{array}{l}\text { Resilience is a "firm's ability to effectively } \\
\text { absorb, develop situation-specific responses } \\
\text { to, and ultimately engage in transformative } \\
\text { activities to capitalize on disruptive } \\
\text { surprises that potentially threaten } \\
\text { organization survival" (p. } 244 \text { ) }\end{array}$ \\
\hline \multirow[t]{3}{*}{ Anticipation } & Somers & 2009 & $\begin{array}{l}\text { Organizational } \\
\text { resilience } \\
\text { potential }\end{array}$ & $\begin{array}{l}\text { Resilience "is more than mere survival; it } \\
\text { involves identifying potential risks and } \\
\text { taking proactive steps (...) to ensure that an } \\
\text { organization thrives in the face of } \\
\text { adversity" (p. 13) }\end{array}$ \\
\hline & $\begin{array}{l}\text { Boin and } \\
\text { Eeten }\end{array}$ & 2013 & $\begin{array}{l}\text { Precursor } \\
\text { resilience }\end{array}$ & $\begin{array}{l}\text { Precursor resilience "prevents budding } \\
\text { problems from escalating into a full-blown } \\
\text { crisis or breakdown" (p. } 431)\end{array}$ \\
\hline & $\begin{array}{l}\text { Ortiz-de- } \\
\text { Mandojana } \\
\text { and Bansal }\end{array}$ & 2015 & $\begin{array}{l}\text { Organizational } \\
\text { resilience }\end{array}$ & $\begin{array}{l}\text { Resilience is "the incremental capacity of an } \\
\text { organization to anticipate and adjust to the } \\
\text { environment" (p. 6) }\end{array}$ \\
\hline
\end{tabular}


ability to resist adverse situations and/or the ability to recover after disturbances and return to a normal state (e.g., Horne 1997; Horne and Orr 1998; Robert 2010). For example, Robert defines organizational resilience as "a firm's capacity to maintain or restore an acceptable level of functioning despite perturbations or failures" (Robert 2010, p. 13). While the first case implies that disturbances have no significant consequences as they fall within a firm's coping range (impact resistance), the second case means that a firm is able to recover from impacts that have exceeded the boundaries of a firm's coping range (rapidity) (Linnenluecke et al. 2012). In both cases, "the emphasis is generally on coping strategies and a quick ability to resume expected performance levels" (Lengnick-Hall et al. 2011, p. 244). Limnios et al. (2014) describe this organizational behavior as "strategic defense" and point to negative consequences that are determined by the system state. They argue that in an undesirable system state, this manifestation of resilience can lead to system rigidity and "dysfunctional momentum" (Miller and Friesen 1980).

A second group of scholars looks beyond the maintenance and restoration of organizational functionality and focuses on the advancement of organizational processes and capabilities (e.g., Robb 2000; Lengnick-Hall and Beck 2005; Lengnick-Hall et al. 2011). These researchers indicate the need to make adjustments to any changes to come out of the crisis stronger than before. For example, Lengnick-Hall et al. (2011) define organizational resilience as "a firm's ability to effectively absorb, develop situation-specific responses to, and ultimately engage in transformative activities to capitalize on disruptive surprises that potentially threaten organization survival" (p. 244). According to this perspective, organizational resilience can be understood as active and purposeful coping with unexpected events. Resilient organizations possess a set of capabilities that enables them to adapt, integrate, and reconfigure internal and external resources and competences to match the requirements of changing conditions [which Teece et al. (1997) call dynamic capabilities]. In this context, some authors talk about a "strategic offense" (Limnios et al. 2014) or "strategic resilience" (Hamel and Vaelikangas 2003; Vaelikangas and Romme 2013) that enables firms to "dynamically reinvent business models and strategies as circumstances change" (Hamel and Vaelikangas 2003, p. 52).

A few scholars go one step further and incorporate the notion of anticipation into their descriptions of organizational resilience (e.g., Rerup 2001; McManus et al. 2008; Somers 2009). Wildavsky (1991) defines anticipation as the "prediction and prevention of potential dangers before damage is done" (p. 77) and contrasts the term with resilience, which he defines as the "capacity to cope with unanticipated dangers after they have become manifest, learning to bounce back". Consequently, Wildavsky understands resilience as a feasible alternative to crisis prevention. Other authors argue that anticipation and resilience are not polar opposites. Kendra and Wachtendorf (2003) state that organizations achieve resilience through preparation, taking into account that preparation does not refer to a specific event but helps to develop capabilities and functions that are necessary to deal with any kind of unexpected event. Recently, Somers (2009) has argued that "resilience is more than 
mere survival; it involves identifying potential risks and taking proactive steps to ensure that an organization thrives in the face of adversity" (p. 13).

In summary, it can be said that, to this day, many studies describe resilience as defensive response (resistance and/or recovery), but there is currently a perspective shift occurring. Especially newer studies expand their perspectives. They describe resilience as rather offensive response (adaptation) or even include the notion of anticipation. While most resilience studies focus on only one of the three described perspectives, some scholars refer to two different perspectives arguing that there are different types of resilience, e.g., precursor or recovery resilience (Boin and van Eeten 2013) which refer to the anticipation and recovery perspectives. Others discuss different manifestations of resilience, e.g., resilience as a kind of resistance or a kind of adaptation (Limnios et al. 2014). Recently, a few studies have started to include two or more perspectives in one resilience definition (McManus et al. 2008; Burnard and Bhamra 2011; Ortiz-de-Mandojana and Bansal 2016; Williams et al. 2017). These studies suggest that the different perspectives are all part of resilience and that they can lead to growth in the face of crisis only in combination. We follow this assumption and combine the active response perspective (which includes purposeful coping and adaptation) with the anticipation perspective. Consequently, we define organizational resilience as an organization's ability to anticipate potential threats, to cope effectively with adverse events, and to adapt to changing conditions. This ability is critical for organizational success (Horne 1997; Coutu 2002). Depending on its specific configuration, resilience can be a source of sustainable competitive advantage (Hamel and Vaelikangas 2003; Sheffi 2007) and, thus, explain why some firms are more successful than others.

\subsection{Previous conceptualizations of organizational resilience}

In the literature, there is little consensus regarding the conceptualization of organizational resilience (Kendra and Wachtendorf 2003; Linnenluecke 2017). Based on the different definitions, scholars usually develop their own conceptualization which is oriented to the specific goals of the investigation. There is a lack of an overarching theoretical framework of organizational resilience. Generally, three categories of conceptualizations can de distinguished: those that treat (1) resilience as an outcome, those that explain (2) resilience as a process, and those that focus on (3) resilience capabilities.

Most studies treat resilience as an outcome-when organizations perform well during crisis or bounce back from interruptions (e.g., Horne and Orr 1998). The specific focus of these studies is on sources and factors that distinguish resilient organizations from less resilient ones. One group of scholars merely points to general attributes that may facilitate an organization's resilience. Even when the researchers within this group use different terms, the most frequently mentioned attributes are adequate resources (e.g., Kendra and Wachtendorf 2003; Gittell et al. 2006; Vaelikangas and Romme 2013), redundancy (e.g., Kendra and Wachtendorf 2003), and positive relationships (e.g., Gittell et al. 2006). Another group focuses on collective behaviors as sources of organizational resilience (e.g., Weick 1993; Horne 1997; Horne and Orr 1998; Mallak 1998; Vaelikangas and Romme 2013). 
One of the first and most important conceptualizations stems from Weick (1993). In his study of the Mann Gulch fire disaster, Weick identifies four potential sources of resilience: improvisation and bricolage, virtual role systems, an attitude of wisdom, and respectful interaction. Weick argues that these four principles facilitate collective sensemaking and, therefore, can help to avoid dramatic consequences from unexpected events. To this day, many studies refer to this conceptualization (e.g., Mallak 1998; Weick et al. 1999; Kendra and Wachtendorf 2003). In particular, they build on it to operationalize and measure resilience (e.g., Mallak 1998; Somers 2009). For example, Mallak (1998) develops and tests a scale for measuring resilience using a survey in the health care provider industry. He extends Weick's original concept and finds six factors explaining more than half of the instrument variance: goal-directed solution seeking, avoidance or approaching new situations with skepticism, critical understanding, role dependence, multiple source reliance, and resource access. More recently, some studies focus on specific organizational strategies (Reinmoeller and van Baardwijk 2005; Carmeli and Markman 2011) or processes (Alesi 2008; Crichton et al. 2009; Ates and Bititci 2011; Demmer et al. 2011) as sources of organizational resilience. In sum, it can be said that all these studies provide useful insights into what organizations must have to respond effectively to changes and crises. They identify resources, behaviors, strategies, and processes that may enhance an organization's resilience. Empirical studies typically focus on organizations that show (or not show) resilient outcomes in the face of crisis and use retrospective (case) analyses to identify factors that have had a positive or negative impact on resilience in the particular context. However, they provide less knowledge about how organizational resilience actually works and which elements it contains. Although some authors refer to the identified factors as elements of organizational resilience, these are mainly sources contributing to the development of resilience in organizations (Kantur and İşeri-Say 2012). The internal workings of resilience remain unclear. For example, we do not really know if resilience is "the result of designed processes or perhaps the outcome of improvisation and luck" (Boin and van Eeten 2013, p. 430).

As one of the first researchers, Sutcliffe and Vogus (2003) argue that a process perspective of organizational resilience supplements and enriches prior theories that explain what surviving organizations have or do. Although it is obvious that " $[\mathrm{g}] \mathrm{ood}$ outcomes are not enough to define resilience" (Sutcliffe and Vogus 2003, p. 108), only a few researchers have tried to describe the resilience process in detail. As these process approaches are based on different resilience definitions, they vary in the type and number of suggested process stages. For example, Linnenluecke et al. (2012) understand resilience as impact resistance and recovery (first perspective in our definition part) and, thus, separate anticipatory adaptation (i.e., long-term adjustments to observed or expected impacts from climate change) from resilience (i.e., the capacity to absorb the impact and recover from the occurrence of extreme weather events). Their process-oriented framework of organizational adaptation and resilience consists of five stages: (1) anticipatory adaptation, (2) exposure, (3) recovery and restoration, (4) post-impact determination of the organization's overall resilience, and (5) future adaptation, whereby only phase (3) and (4) refer to resilience. Burnard and Bhamra (2011), in contrast, integrate organizational 
adaptation into their definition of resilience (second perspective in our definition part) and present a conceptual framework for resilient organizational responses to unspecified disruptions. The proposed resilience process comprises three general phases: (1) detection and activation, (2) (resilient) response, and (3) organizational learning. In their description, the authors particularly focus on threat detection and response activation as critical phases within the process. Further process approaches can be found in more practice-oriented papers with a focus on resilience management (McManus et al. 2008; Teoh and Zadeh 2013). For example, McManus et al. (2008) present a resilience management process that consists of three elements (building situational awareness, managing keystone vulnerabilities, and increasing adaptive capacity) and that can serve as a practical guide for improving resilience. Referring to the previously identified components of resilience (anticipation, coping, and adaptation), these approaches provide the most complete picture. Despite the differences, all the process approaches provide important insights into the resilience construct. They define discrete elements of the resilience process and thus contribute to opening the black box between resilience resources (inputs) and resilience outcomes (outputs). Furthermore, they recognize the dynamic nature of resilience and thus provide a foundation for studying the longterm development of organizational resilience. Nevertheless, there is a lack of an overarching process framework that highlights individual elements of the different resilience phases and, thus, can be used as a basis for future research.

Many scholars have defined resilience as an organizational ability (see Table 1). However, only a few of them provide deeper insight into specific capabilities that underlie resilience. Previous studies on resilience capabilities are extremely heterogeneous: They refer to different contexts, focus on specific problems, and use different research methods. Using two case studies in manufacturing-based SMEs, Ismail et al. (2011) show that resilience results from the development of both operational and strategic capabilities. Lengnick-Hall and Beck (2005, 2009) and Lengnick-Hall et al. (2011) go one step further and focus on general capabilities and routines that underlie organizational resilience. Lengnick-Hall and Beck (2005) explain that a firm's resilience capacity consists of cognitive, behavioral, and contextual elements and results from using different organizational routines in dealing with uncertainty and complexity. Based on this, Lengnick-Hall et al. (2011) note that a firm's resilience capacity “is derived from a set of specific organizational capabilities, routines, practices, and processes by which a firm conceptually orients itself, acts to move forward, and creates a setting of diversity and adjustable integration" (p. 245). In this conceptual paper, they particularly focus on the role of strategic human resource management practices for developing organizational resilience. Recently, Ortiz-de-Mandojana and Bansal (2016) also mention that organizational resilience is not a static attribute, but a latent, path-dependent set of capabilities that organizations develop through coping with unexpected events. Using a matched-pair design, they demonstrate that social and environmental practices associated with business sustainability help firms to sense and mitigate threatening situations, a process that contributes to organizational resilience. Overall, capability-based studies offer important insight into how resilience may be achieved in practice. They provide insight into the internal workings of resilience 
and conditions for its development. However, none of these studies focus on resilience capabilities that underlie the different phases of the resilience process. It is the aim of our paper to close this research gap.

\section{A new conceptualization of organizational resilience}

Most of the resilience literature is prescriptive and normative (Boin and van Eeten 2013; Duit 2016). Studies particularly focus on attributes, resources, or behaviors that seem to distinguish resilient from less resilient organizations (Sutcliffe and Vogus 2003). Thus, we do not really know how resilience may be achieved in practice. For example, it remains unclear how-and to what extent-resilient organizations can be designed (Duit 2016). However, there are two promising approaches that may enhance our knowledge: (1) processual approaches define different resilience stages and recognize the dynamic nature of resilience and (2) studies on resilience capabilities provide insight into the internal workings of resilience. We assume that, in combination, these two approaches can foster a comprehensive understanding of the resilience phenomenon and create a profound basis for empirical research on the emergence of resilient organizations. For this reason, we build on the 'resilience-as-a-process' perspective and combine it with the idea of resilience as a unique blend of organizational capabilities and routines. It is our aim to develop a conceptual framework that illustrates the main stages of the resilience process and points to underlying capabilities that together constitute the meta-capability of organizational resilience. Furthermore, we explain interrelationships of the different resilience stages as well as main antecedents and drivers.

\subsection{Fundamentals of the framework}

As a first step towards our framework, we need to define the resilience process. For this purpose, we build on process-oriented studies that point to "the dynamic nature of resilience as an interaction between the organization and the environment" (Williams et al. 2017, p. 20). From this perspective, resilience means to effectively respond to adverse events, not only after adverse events, but before, during, and after as well (e.g., Linnenluecke et al. 2012; Alliger et al. 2015; Williams et al. 2017). Accordingly, we suggest three successive stages of the resilience process (see Fig. 1) and argue that resilient organizations respond not only to the past (reactive action) or to current issues (concurrent action), but also to the future (anticipatory action). This temporal structuring of the resilience process follows similar approaches within the crisis management literature (e.g., Pearson and Clair 1998; James and Wooten 2005; Boin et al. 2005).

To describe the three resilience stages in more detail, we follow studies that understand organizational resilience as offensive response to unexpected events (adaptation) (e.g., Weick et al. 1999; Lengnick-Hall et al. 2011; Limnios et al. 2014) instead of a defensive response (resistance and/or recovery). This means that the first stage of the resilience process refers to the attempt to anticipate critical developments and potential threats and be prepared (e.g., Somers 2009; Boin and 


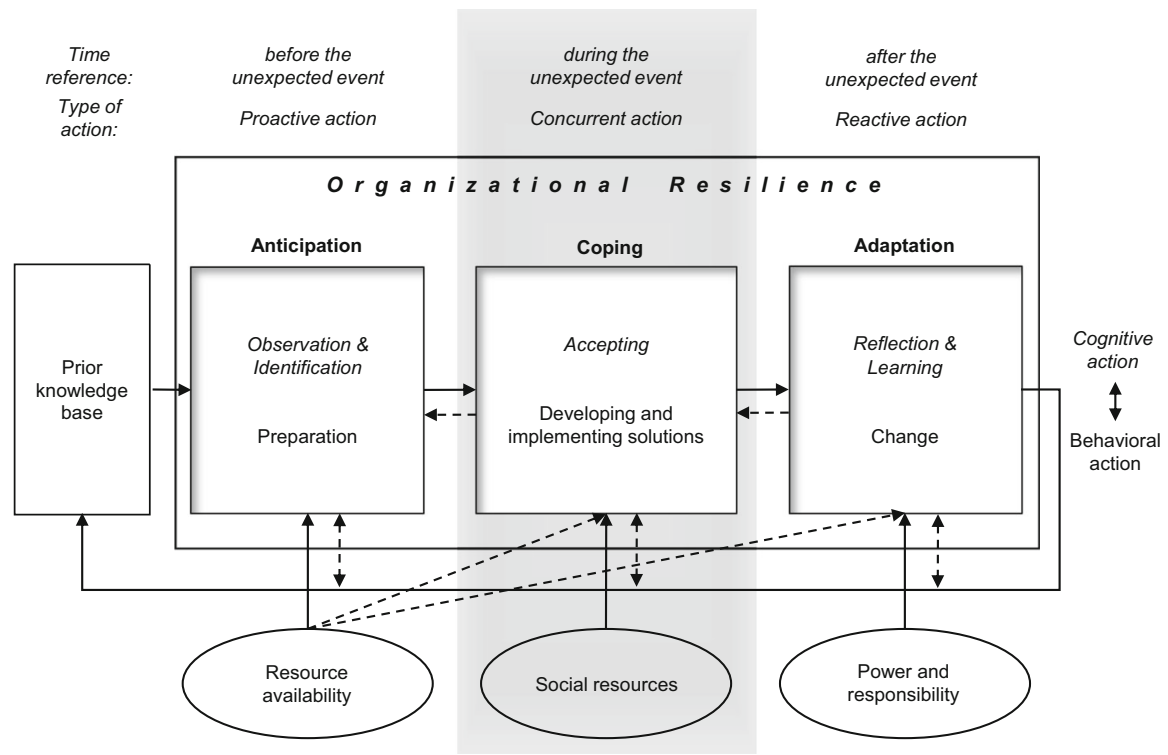

Fig. 1 A capability-based conceptualization of organizational resilience

van Eeten 2013). Beyond that, an offensive response comprises a purposeful coping during critical situations (e.g., Wildavsky 1991; Weick et al. 1999; Rerup 2001) as well as some kind of adaptation, transformation, or learning after critical situations have occurred (e.g., Weick et al. 1999; Lengnick-Hall et al. 2011). Based on this, we refer to the three resilience stages as anticipation, coping, and adaptation and thereby follow recent studies that have begun to combine these connotations and integrate them in one resilience definition (Hamel and Vaelikangas 2003; McManus et al. 2008; Ortiz-de-Mandojana and Bansal 2016; Williams et al. 2017).

Building on this process perspective, we can identify organizational capabilities that underlie the three stages of the resilience process and together form organizational resilience. This means that resilience can be conceptualized as a meta-capability consisting of a set of organizational capabilities/routines that allow for a successful accomplishment of the three resilience stages. This focus on resilience capabilities provides a deeper understanding of the nature and development of a firm's resilience capacity. Organizational resilience capabilities develop over time and emerge from the process of coping with threatening situations and unexpected events (Linnenluecke et al. 2012). They are complex, deeply embedded in an idiosyncratic social context, and represented by various collective routines that generate resilience outcomes. Traditionally, organizational routines have been seen as the outcome of intentional design (March and Simon 1958; Cyert and March 1963) or complex evolutionary processes (Nelson and Winter 1982). In new research streams, they are rather seen as complex social practices (Nicolini et al. 2003; Schultze and Orlikowski 2004; Gherardi 2006). Focusing on resilience capabilities, routines, or practices allows for a better understanding of the actual 
behaviors of resilient organizations, and it can help to explain why some organizations are better able to cope with unexpected events than others.

\subsection{Resilience capabilities}

Thus far, only a few studies have investigated resilience capabilities in organizational resilience research. Therefore, to describe the capabilities behind the individual resilience stages, we cannot rely solely on this research stream. Instead, we have to expand our search activities to other related areas (e.g., crisis management and innovation management) as well as to disciplines that address other resilience levels (e.g., public administration). In particular, we have to integrate findings from research areas that specify individual resilience stages: e.g., studies on high reliability organizations (HROs) (anticipation), crisis management (coping), and organizational learning from unexpected events (adaptation). Below, we will elaborate on the main capabilities of each resilience stage and give examples of resilience-enhancing practices. After that, we address relationships and interactions of the different resilience stages as well as main antecedents and drivers.

\subsubsection{Anticipation capabilities}

Anticipation is the first dimension of organizational resilience and describes its preventive aspects relative to a disturbance. It refers to the ability to detect critical developments within the firm or in its environment and to adapt proactively (Somers 2009; Ferreira et al. 2011; Teixeira and Werther 2013). This does not mean that resilient organizations can prevent every failure or crisis. Crises often do not announce their arrival. However, some firms are able to see the unexpected faster than others, and they are able to immediately react to it while others "wait and see". Madni and Jackson (2009) indicate that systems need anticipation capabilities to avoid threatening situations or at least minimize potential negative consequences. They define anticipation as "the ability to 'look down the line' to determine how the environment is expected to change with a view to making decisions and taking actions in the present that promote desirable outcomes and circumvent disruptions in the future" (p. 187). Based on prior studies that include the notion of anticipation in their definition of resilience (Kendra and Wachtendorf 2003; Somers 2009; Burnard and Bhamra 2011), we assume that the anticipation stage comprises three specific capabilities: the ability to observe internal and external developments, the ability to identify critical developments and potential threats, and-as far as possible-to prepare for unexpected events.

Observation and identification are closely related and, thus, considered together. Researchers agree that those capabilities are important for resilience. They argue that organizations must recognize early signals of crisis to respond quickly and, thus, avoid escalation (e.g., Ortiz-de-Mandojana and Bansal 2016). However, they use different concepts to describe these capabilities. For example, Burnard and Bhamra (2011) use the notion of threat detection which is related to both the environmental feedback controls and the assessment of operating conditions. In the 
literature, these capabilities are also discussed as the acquisition of weak signals and environmental scanning (e.g., Ansoff 1975; Day and Schoemaker 2005; Ilmola and Kuusi 2006; Uskali 2005). As Ansoff (1975) mentions, discontinuities can be identified through a systematic perception of weak signals, i.e., information about emerging issues without knowing their actual importance and scope. The activity used to look for weak signals is called environmental scanning (Hiltunen 2008). It is defined as an activity for acquiring information that involves exposure to and perception of information (Aguilar 1967). "The activity could range from gathering data in the most deliberate fashion - as by an extensive market research programto undirected conversation at the breakfast table or the chance observation of an irate housewife throwing your product into trash barrel" (Aguilar 1967, p. 18). Although some authors point to environmental scanning as source or part of the resilience process (Burnard and Bhamra 2011; Demmer et al. 2011), little is known about how resilient organizations actually acquire external information. However, the absorptive capacity literature gives some useful insights into successful practices of (external) knowledge acquisition. For example, Lewin et al. (2011) describe the ability to recognize and identify the value of outside knowledge as an external metaroutine of absorptive capacity and provide examples of underlying practiced routines, such as market research, end-user surveys, and the use of gatekeepers. With a focus on potentially threatening developments, such routines might also be useful for the development of organizational resilience. In the resilience context, Ortiz-de-Mandojana and Bansal (2016) could show that sustainable business practices - that means organizational practices with a positive effect on social and natural environments-help firms to sense and mitigate threatening situations. For example, investments in reliable high-quality goods can lead to trustful customer relationships in which sensitive information are shared openly. In addition to the observation and identification of actual changes and upcoming crisis, a focus on potential future developments is important. For example, scenario planning practices can help firms to think about different futures-even if they are unrealistic or unthinkable_-and ways to handle them (e.g., Hillmann et al. 2018). In sum, observation and identification capabilities help firms to see and react to changes before their full impact becomes visible.

Preparation is a term that has been used by Weick et al. (1999) to describe an ability specific to HROs. HROs are technologically complex organizations operating in high-risk environments, in which even small failures can have dramatic consequences (e.g., nuclear power plants, aircraft carriers, or chemical firms). In such organizations, failure prevention takes top priority and "performance reliability rivals productivity as a dominant goal" (Roberts 2010, p. 102). However, preparation capabilities are not only important for HROs but also for resilient organizations (e.g., Kendra and Wachtendorf 2003; Somers 2009). "For organizations, being prepared means that a firm or agency is equipped to deal with unforeseen adversity and it is ready to capitalize on unexpected opportunities" (Lengnick-Hall and Beck 2009, p. 3). This means that preparation capabilities help to develop resources that are necessary in times of crisis (e.g., suitable recovery plans, effective relationships, and mutual understanding). Important insights into this part of resilience can be gained from risk management, emergency planning, 
and business continuity management (BCM). Especially BCM-as a recent evolution of risk-based practice (Elliott et al. 1999, 2002; Herbane et al. 2004) provides important insights into how organizations can prepare for critical events; for example, how organizations can develop suitable recovery plans for previously identified critical business operations (Randeree et al. 2012). Training and simulation practices can ensure that the benefits and objectives of such plans are achieved (Gibb and Buchanan 2006). For example, those practices support organizational members to learn complex procedures and develop personal and collective action repertoires (Lengnick-Hall et al. 2011). However, it is not solely the developed plans and formal procedures that prepare organizations for the great variety of unexpected events. Such events often do not correspond with planning assumptions and require intuitive acting and ad hoc decisions (Seville et al. 2008; Boin and McConnell 2007; Bhamra et al. 2011). "The most important benefit of preparing the plan is the growing of effective relationships and mutual understanding among those involved in the plan preparation process" (Crichton et al. 2009, p. 32). Thus, preparation does not mean planning for the unexpected-this is impossible. Rather, it means that organizations prepare without knowing if, when, or where an unexpected event will occur in the future. Such a preparation capability may be developed "by expanding general knowledge and technical facility, and generalized command over resources” (Wildavsky 1991, p. 221).

In sum, anticipation capabilities build a resilience potential which can be defined as "resilience that is not presently evident or realized" (Somers 2009, p. 13). Anticipation capabilities build the foundation for an effective response to critical situations and thus realized resilience; however, they provide control only to a limited extent and "important actions, adjustments, and decisions must be undertaken in real time" (Schulman 2004, p. 43). Thus, organizations also need to develop coping capabilities. The next section concentrates on the processes behind this real-time coping with unexpected events.

\subsubsection{Coping capabilities}

In addition to the anticipation of and preparation for critical events, resilience also means coping "with unanticipated dangers after they have become manifest" (Wildavsky 1991, p. 77). In the literature, there are many synonyms for coping with unexpected events: e.g., dealing with unknown hazards (Wildavsky 1991), responding productively to significant change (Horne and Orr 1998), or designing and implementing positive adaptive behavior matched to the immediate situation (Mallak 1998). Clearly, all these terms refer to an effective handling of unexpected events so as to resist destruction. The overall ability to cope with the unexpected is closely related to crisis (incident) management and can be separated into two subcategories: the ability to accept a problem and the ability to develop and implement solutions (see, e.g., Smart and Vertinsky 1977; Reilly 1993; Jaques 2007). These capabilities imply immediate or short-term action in response to unexpected events (Madni and Jackson 2009).

Accepting The notion that coping with unexpected events starts with accepting the problem has already been suggested in the literature on individual resilience. For 
example, Coutu (2002) states that resilient people display, among other things, a staunch acceptance of reality. At the organizational level, this phenomenon is discussed as "the cognitive challenge" (Hamel and Vaelikangas 2003, p. 54). It is argued that critical events, even if they are predictable, often come as a surprise because organizations take refuge in denial. This means that, "for many organizations, the future is less unknowable than it is unthinkable" (Hamel and Vaelikangas 2003, p. 55). The negative consequence is that organizations require too much time to realize and act on those events. For this reason, organizations need to develop the ability to accept a problem. Only then can they face critical situations and react quickly. In this context, Weick (1993) already pointed out that organizations, to accept reality, need an attitude of wisdom. Resilient organizations are not too confident or too cautious; they use their experiences, but also know their limits and invite doubt. Catalan and Robert (2011) propose that the acceptance dimension of organizational resilience is comprised of three elements: understanding the environment in which the system operates, defining a reference state for the system, and being aware of and accepting system failures. These elements show some overlap with the previously discussed anticipation capabilities. Thus, it can be assumed that anticipation and coping capabilities are closely connected and that the promotion of anticipation capabilities may also have positive effects on the ability to accept a problem. So far, we know little about how the ability to accept failures is actually enacted and how organizations can develop this organizational ability.

Developing and implementing solutions When a crisis occurs, organizations must put their crisis plans into action and develop ad hoc solutions (Pearson and Clair 1998). Developing solutions in the face of crisis is always a combination of sensemaking and acting (Weick et al. 2005). "The basic idea of sensemaking is that reality is an ongoing accomplishment that emerges from efforts to create order and make retrospective sense of what occurs" (Weick 1993, p. 635). Sensemaking means that individuals or groups try to make things rationally accountable to themselves and others. Only if people understand the crisis situation are they able to act on it. For effective sensemaking, there must be continual feedback between understanding and action, which means that sense must continually be made and remade. Resilience researchers have already emphasized that collective sensemaking is an important element of (cognitive) resilience (e.g., Lengnick-Hall and Beck 2009; Lengnick-Hall et al. 2011; Linnenluecke et al. 2012) and much can be learned from the various studies that provide insights into the functioning of sensemaking in organizations (e.g., Maitlis 2005; Patriotta 2003; Maitlis and Christianson 2014).

One of the most important principles to facilitate the collective sensemaking process is 'bricolage' (Weick 1993): the capability to improvise and to solve problems creatively (Kendra and Wachtendorf 2003). What first sounds counterintuitive- to improvise in already chaotic situations-can help to prevent catastrophe. In his study on the Mann Gulch fire disaster, Weick (1993) argues that improvisation makes organizations less vulnerable since it allows for a recombination of those actions that are already in the organization's repertoire into novel combinations. Accordingly, if an organizational order fails in a crisis situation, a substitute might be developed immediately. In their paper on HROs, Weick et al. (1999) explain that bricolage may be enacted through informal "epistemic 
networks" (Rochlin 1989). "Knowledgeable people self-organize into ad hoc networks to provide expert problem solving" (Weick et al. 1999, p. 100). These ad hoc networks are not formalized and they dissolve when the disturbance has been managed. Bourrier (1996) describes these structures as "informal latent networks activated only in the face of uncertainties and rapidly developing contingencies as a supplement to the normal patterns of formal hierarchy and compliance with strict roles" (p. 105). Consequently, such networks may help to quickly combine the knowledge that is necessary to cope effectively with events that cannot be predicted. In disaster research, similar organizational forms are discussed as emergent (response) groups (Drabek and McEntire 2003; Tierney 2003; Majchrzak et al. 2007).

However, the ability to develop solutions not only means idea generation, but also coordination. During times of severe adversity, when decisions must be made promptly and failures could have dramatic consequences, both formal and informal coordination mechanisms are important (Faraj and Xiao 2006). On the one hand, firms need formal structures and clear responsibilities for quick decision making and immediate response. On the other hand, firms also need openness and freedom for flexible and creative action. Faraj and Xiao (2006) explore how coordination occurs in a medical trauma center-a so-called fast-response organization-and describe two types of coordination practices. They argue that expertise coordination practices (reliance on protocols, community of practice structuring, plug-and-play teaming, and knowledge sharing) are necessary to manage the distributed knowledge and ensure the timely application of the needed expertise. They further suggest that dialogic coordination practices (epistemic contestation, joint sensemaking, cross-boundary intervention, and protocol breaking) are time-critical responses to unexpected events that ensure failure-free operations. In this context, Gittell (2002) shows that the performance effects of coordination mechanisms (e.g., team meetings) are mediated by relational coordination, a relationship-intensive form of coordination.

Overall, the ability to develop solutions allows for coordinated collective responses to adverse events (e.g., quick understanding and creative combination of knowledge). However, this also requires that the developed solutions are actually implemented. "(i)mplementation-is the pragmatic phase of (...) problem solving" (Dayton 2004, p. 179) and means the ability of an organization to actually realize a previously developed solution. Especially crisis situations require precise and quick implementation (Smart and Vertinsky 1977); however, research shows that newly developed solutions-regardless of how carefully they are designed-do not automatically lead to changes in the organizational patterns of action (Feldman 2003; Howard-Grenville 2005; Pentland and Feldman 2008). To ensure actual changes, the developed solutions must be widely accepted and adopted; thus, the support of the whole organization is needed. The previously mentioned coordination mechanisms seem to play an important role in implementing solutions. They can help to achieve a system-wide alignment and thus a "whole-system response" (Horne and Orr 1998, p. 30). 


\subsubsection{Adaptation capabilities}

Beside the first two phases, resilience also includes the ability to adapt to critical situations and to use change for own purposes. This ability refers to adjustments following crises and is directed toward organizational advancement (Limnios et al. 2014). This type of long-term learning (Madni and Jackson 2009) increases the knowledge base of a firm, which in turn acts as a main antecedent for the anticipation dimension (see Fig. 1 and the detailed discussion in Sect. 3.4). Therefore, adaptation is one of the key capabilities that can help organizations avoid or reduce negative consequences from unexpected events (Carley 1991; Carley and Harrald 1997). Adaptation includes two types of capabilities: (1) reflection and learning and (2) organizational change capabilities.

Reflection and learning To use failure experience for own purposes, both cognition and behavior are essential. On the one hand, organizations must be able to reflect on the crisis situation and to incorporate the gained insight into the existing knowledge base. On the other hand, they must be able to act on this knowledge and produce change (Edmondson 2002). "Reflection is the process of stepping back from an experience to ponder, carefully and persistently, its meaning to the self through the development of inferences; learning is the creation of meaning from past or current events that serves as a guide for future behavior" (Daudelin 1997, p. 39). Different studies provide insight into the specific role of reflection within the learning process. For example, Daudelin (1997) suggests four stages in the reflection process: articulation of the problem, analysis of the problem, formulation of a theory to explain the problem, and action. She also mentions different reflection practices that may facilitate learning from experience (e.g., problem-solving meetings, project review sessions, or informal discussions with friends/colleagues). Learning can be described as "ongoing process of reflection and action characterized by asking questions, seeking feedback, experimenting, reflecting on results, and discussing errors or unexpected outcomes of actions" (Edmondson 1999, p. 353). Although previous research comprises several case studies of organizations that have learned from unexpected events (e.g., Roberts et al. 2005; Rochlin et al. 1987) and organizations that have failed to learn from unexpected events (e.g., Sagan 1993; Vaughan 2005), there is only little empirical work on concrete practices by which organizations learn from incidents (Lindberg et al. 2010). Vastveit et al. (2015) provide insight into actual practices used to improve safety performance in a Scandinavian refinery after unexpected incidents. They found that incident learning did not just happen through formal incident management processes, but also through daily work practices. They show that employees executed learning-related tasks in different ways from formal presentations of reports and risk-reducing measures to informal meetings and discussions raising the reflexivity of employees. Gressgård and Hansen (2015) point to the important role of interaction and collaboration for learning from failures. In particular, they could show that knowledge exchange between units is an important predictor of perceived ability to learn from failures. With their in-depth analysis of post-flight reviews in a fighter squadron of the Israel Defense Force, Ron et al. (2006) provide deep insight into the specific practice of after-action reviews. 
Furthermore, organizations can learn from the vicariously experienced incidents from related or similar organizations (Kim and Miner 2007; Madsen 2009). This is particularly important since "[a]ny failure that occurs in one system will have a propensity to recur in another 'like' system for similar reasons" (Toft and Reynolds 1994, p. 4) - a phenomenon called isomorphism. Researchers show that accident rates for US airlines and railroads decline with an increase in the number of accidents experienced by other firms in the same industry (Haunschild and Sullivan 2002; Baum and Dahlin 2007) and that hotel chains learn from their industry's operative and competitive experiences (Ingram and Baum 1997). Although there is limited evidence, it can also be assumed that failures in other industries are important learning sources (Aldrich 1999; Kim and Miner 2007; Crichton et al. 2009). Focusing on the banking industry, Kim and Miner (2007) show that even near-failure experiences can generate vicarious learning. However, until now, there has been little empirical research on how vicarious learning works in the case of unexpected events. Some studies provide insight into how governments and private organizations assimilate unexpected events experienced by other firms and extract "lessons learned" from them (e.g., Kirchsteiger 1999; Roberts and Bea 2001; Weber et al. 2001). For example, they describe typical lessons learned processes such as information collection, verification, storage, and dissemination and point to used artifacts such as incident reports, organization stories, and alerts. However, the generation of lessons learned does not necessarily mean effective learning from (vicarious) failure experience. Research shows that organizations tend to focus on the surface, concentrating on active failures, rather than conducting deep analyses and uncovering problematic latent conditions (Haunschild and Sullivan 2002). As a result, organizations often generate new knowledge (lessons learned), but fail to translate this knowledge into new behaviors. Creating diversity in perspectives can force organizations to avoid simple interpretations through constructive conflict and deeper discussions about actions to take (Haunschild and Sullivan 2002; Gressgård and Hansen 2015).

Organizational change Overall change can only be achieved by higher-level learning (e.g., Fiol and Lyles 1985)—also called second-order learning (e.g., Sørensen 2002) or deutero learning (e.g., Visser 2007)—which results in the development of new norms, values, and practices. This higher-level learning implies a cultural readjustment (Turner 1976); the organization's view of the world must change to stimulate a shift in beliefs and precautionary norms (Stead and Smallman 1999). Kendra and Wachtendorf (2003) argue that resilient organizations show "a willingness to overturn or bypass experience, knowing that the current troublesome situation, although similar to those encountered previously, may in fact have quite novel features that require enquiry and ingenuity to address" (pp. 42-43). Therefore, organizations need to be able to simultaneously believe in and question their past experience (Weick 1969). This is necessary to be able to adapt to unexpected events, as Ryle (1979) points out: "(T)o be thinking what he is here and now up against, he must both be trying to adjust himself to just this present onceonly situation and in doing this to be applying lessons already learned" (p. 129).

To produce organizational change it is particularly important to actually act on previously generated knowledge. Organizations must be able to exploit a newly 
developed solution and transfer it to their individual parts. To achieve that, change management capabilities are needed. For example, it could be shown that an organization's change management process is fundamental to organizational resilience (Ates and Bititci 2011). Other scholars point to the importance of a robust strategic planning process with an entrepreneurial focus (Demmer et al. 2011). In this context, organizations must also be aware that putting new knowledge into practice can create new problems or necessitate further changes. "Studies have shown that two out of three change initiatives fail" (Sirkin et al. 2005, p. 109). Hence, how change is managed is critical to resilience (Ates and Bititci 2011). As every other organizational change, change in response to unexpected events may result in different types of resistance. Thus, adaptation involves not only making important changes but also overcoming resistance to change (Dayton 2004). Resistance to change may be rooted in the individual (e.g., Piderit 2000), team (e.g., Janis 1982), or organizational levels (e.g., Lorsch 1986). To overcome the specific manifestations of resistance, various change management practices can be applied. Soft managerial practices such as effective communication and relationships within the organization seem to be particularly important to enhancing an organization's resilience (Seville et al. 2008). Furthermore, the ability to change can find expression in the successful use of so-called "change agents", which accompany the change and implementation process and, if necessary, have intervention methods and options (Jones 2006).

\subsection{Relationships and interactions of resilience capabilities}

\subsubsection{Interactions of resilience stages}

It is important to mention that the three resilience stages cannot be clearly separated. The resilience stages show some overlaps and strongly depend on each other. For example, the anticipation stage is closely linked with the coping stage. On the one hand, it is important to anticipate change to be able to quickly and successfully act on it. On the other hand, organizations with a broad range of action also show a broad range of perception of critical developments and threats (Weick et al. 1999). This idea originally stems from Westrum (1988) and his 'ecology of thought'. He argues that organizations with a willingness to act on specific threats are also organizations with a willingness to see potential threats and think about them (Weick et al. 1999). Furthermore, the coping stage is closely linked with the adaptation stage. Coping with crises builds the foundation for reflection, learning, and change. Organizations learn from the crisis itself as well as the coping process. For example, successful coping allows for learning from success and unsuccessful coping allows for learning from failure. In turn, both types of learning may enhance an organization's coping capabilities by broadening its spectrum of actions. In sum, it can be said that the three resilience stages build on each other (anticipation influences coping and coping influences adaptation). However, there is also a backward influence. 


\subsubsection{Potential and realized resilience}

We suggest that for high levels of organizational resilience, it is not enough to develop one of the underlying resilience capabilities or to focus on one stage in the resilience process. Organizations need to develop capabilities of all three resilience stages that together form the meta-capability of organizational resilience. They need anticipation capabilities to cope with crisis in the future (e.g., Somers 2009). These capabilities help to identify potential risks and take proactive steps against them. It can be said that anticipation capabilities lead to the development of a resilience potential-that means "resilience that is not presently evident or realized" (Somers 2009, p. 13). Anticipation capabilities are necessary but not sufficient for the development of organizational resilience; they only build the foundation for effective responses to critical situations. However, organizations must also possess coping capabilities to realize their resilience potential. For example, they must be able to apply their crisis plans and use their collective knowledge to develop crisisspecific solutions. Furthermore, there is no resilience without some learning after critical events or crises. Learning is necessary to adapt to changes, transform prior knowledge, and develop capabilities that underlie the first two resilience stages (Madni and Jackson 2009; Lengnick-Hall et al. 2011). In sum, it can be said that, to achieve high levels of resilience, organizations must develop both a high resilience potential and the ability to realize and continuously enhance this potential. Especially this interaction of potential and realized resilience can explain why some firms are more successful in dealing with crises than others.

\subsubsection{Cognitive and behavioral dimensions}

Connecting the gained insights with the differentiation of cognitive, behavioral, and contextual dimensions of resilience (Lengnick-Hall and Beck 2005, 2009; Lengnick-Hall et al. 2011), it can be said that the three resilience stages always contain cognitive and behavioral dimensions, and that the successful completion of those stages always depends on an interplay between cognitive and behavioral capabilities and actions. Cognitive capabilities (e.g., mindfulness, sensemaking, and critical reflection) are needed to understand environmental developments and make appropriate decisions. In this context, Hamel and Vaelikangas (2003) talk about the 'cognitive challenge'. "A company must become free of denial, nostalgia, and arrogance. It must be deeply conscious of what's changing and perpetually willing to consider how those changes are likely to affect its current success" (Hamel and Vaelikangas 2003, p. 4). Behavioral capabilities (e.g., improvisation, experimentation, and knowledge implementation) ensure that resources are used and necessary actions are taken. They are "the engine that moves an organization forward" (Lengnick-Hall and Beck 2005, p. 781). Our conceptualization shows that each resilience stage demands cognitive actions to generate and select action alternatives, and behavioral actions to implement the best alternatives and respond effectively to the crisis situation. This means that resilient organizations can only emerge when cognition and behavior are in conjunction. It is not enough to change behavior without any cognitive development or to create knowledge without any 
accompanying change in behavior (Fiol and Lyles 1985). Beside the interplay of cognitive and behavioral elements of resilience, contextual factors (e.g., resources, social capital, and power) are important to the successful accomplishment of the three resilience stages as well as the development of resilience capabilities. The next section provides insight into the core conditions for successful resilience processes.

\subsection{Main antecedents and drivers}

Organizational capabilities that underlie the three resilience stages-and thus the meta-capability of organizational resilience-depend on various context factors. As mentioned earlier, resilience capabilities are extremely complex and deeply embedded in social contexts, which means that it is far from easy to define relevant factors and conditions for their accomplishment and development. However, there are some main antecedents (knowledge base) and drivers (resource availability, social resources, and power/responsibility) that are of particular importance.

\subsubsection{Knowledge base}

An important role in the resilience process plays the organization's knowledge base. From the innovation literature, we already know that anticipation capabilities largely depend on a firm's prior knowledge base, which enables and hinders the acquisition of new knowledge equally (Cohen and Levinthal 1990). On the one hand, this prior knowledge base facilitates a firm's discernment of knowledge by defining the locus of knowledge search (Rosenkopf and Nerkar 2001). On the other hand, prior knowledge restricts a firm's scanning activities to familiar and proximate areas (Cyert and March 1963; Helfat 1994; Stuart and Podolny 1996). Firms might then recognize only external information that is close to their existing knowledge base and ignore other knowledge sources. The result are narrow perceptions inappropriate for uncertain worlds (Beinhocker 1999). Therefore, it could be argued that, to be resilient, organizations should develop a broad and diverse knowledge base to anticipate both internal and external change, even if this knowledge is far away from the organization's core business. This can be ensured by parallel exploration, experimentation, and investments in diversity (Beinhocker 1999).

Beyond that, the other resilience stages also depend on the organization's prior knowledge (e.g., knowledge about the environment, knowledge about former crisis, knowledge about successful actions). A broad and diverse knowledge base can help organizations to develop multiple ideas for crisis reaction and decide for the most suitable solution (see, e.g., Gomes et al. 2014; Pregenzer 2014; Sutcliffe and Vogus 2003). For example, Sutcliffe and Vogus (2003) maintain that experiential diversity can enlarge the ability to grasp a situation and cope with the details. Pregenzer (2014) argues that diversity of skills, personalities, and perspectives can enhance creativity and innovation, which results in an improvement of decision-making and problem-solving (see also Ely and Roberts 2008). A broad and diverse knowledge base can also help organizations to learn from experience and internalize the new 
knowledge. It forces organizations to avoid simple interpretations through constructive conflict and deeper discussions about actions to take (Haunschild and Sullivan 2002). Thus, a diverse knowledge base may reduce the tendency to focus on the surface and promote the organizational function logic instead of individual blame (Catino 2008) when explaining failures (Gressgård and Hansen 2015).

Furthermore, the knowledge base serves as a mediator between the adaptation and anticipation phases. If an organization is able to learn from crisis situations and adapt to that, it can extend its knowledge base and thus foster its anticipation capabilities. Moreover, all resilience phases have an influence on the knowledge base since learning not only happens in the aftermath of an unexpected event. Rather, each resilience phase includes some kind of learning-learning for crisis (anticipation), learning as crisis (coping), or learning from crisis (adaptation) (see also Smith and Elliott 2007). Along these lines, Christianson et al. (2009) differentiate between learning "from" rare events and learning "through" rare events, the latter occurring while handling the unexpected. In our conceptualization, learning for or through rare events is included in the anticipation and coping dimensions of organizational resilience. The close relationship between these different learning types is illustrated by the feedback loop between the adaptation and anticipation phases. Figure 1 shows that, in each phase of the resilience process, the knowledge base of an organization may be enhanced through learning, which in turn positively influences its resilience capabilities.

Proposition 1 An organization's knowledge base is an important antecedent of organizational resilience. It builds the foundation for the anticipation of critical developments (as well as coping and adaptation). In turn, an organization's knowledge base may be enhanced through the accomplishment of the three resilience stages.

\subsubsection{Resource availability}

Many studies point to the need of a broad and accessible set of resources as a foundation for quick and adequate reactions under challenging conditions (e.g., Hamel and Vaelikangas 2003; Lengnick-Hall and Beck 2009; Vogus and Sutcliffe 2007). In particular, time, financial and human resources are vital to build organizational resilience. First, those resources allow for an effective anticipation of adverse events. To observe the environment and identify critical developments, organization members need time and the allowance to invest their time into scanning activities. If employees are too much involved into operational business and do not have the capacity to scan the environment, the organization would not be able to identify critical developments. Furthermore, environmental scanning and preparation for critical future events require financial (i.e., cash flow) and human resources (i.e., skills) to develop recovery plans, simulate crisis management, or train employees and leaders. Second, resources are also important to the coping and adaptation phases. For example, financial resources can serve as a buffer or shock absorber and thus contain the negative consequences of a crisis ( $\mathrm{Pal}$ et al. 2014). 
Previous research agrees that financial resources can help to handle acute crises and recover from them (e.g., Burke 2005; de Carvalho et al. 2016; Lampel et al. 2014). Analyzing airline industry responses to September 2011, Gittell et al. (2006) found that airlines with greater financial resources (low levels of debt and high levels of cash on hand) were able to retain staff (instead of laying off staff) and thus had more human resources to recover. In sum, it can be said that organizations need slack resources (Kendra and Wachtendorf 2003; Vaelikangas and Romme 2013; Vogus and Sutcliffe 2007) — a cushion of spare resources which can be flexibly used (Bourgeois 1981). In this respect, organizations also need some degree of redundancy such as unused capacity, multiple sourcing, or parallel processes (see, e.g., Denhardt and Denhardt 2010; Kendra and Wachtendorf 2003; Pal et al. 2014), which allow for adequate functioning even if parts of the organization fail. The important question is at what point the costs of redundancy lose their positive influence and turn into a disadvantage (Linnenluecke and Griffiths 2010).

Proposition 2 Resource availability positively influences the resilience of organizations. Specifically, it fosters the development of anticipation capabilities (as well as coping and adaptation capabilities).

\subsubsection{Social resources}

After the early anticipation of upcoming crises, it is particularly important to react in a resilient manner and develop appropriate solutions to overcome those situations. In this context, social resources are often considered as source of organizational resilience (e.g., Gittell et al. 2006; Powley 2009; Sutcliffe and Vogus 2003). For example, deep social capital can enhance resilience by offering contextual benefits (e.g., information sharing, resource exchange, or crossfunctional collaboration) (Lengnick-Hall and Beck 2009). Social capital helps to achieve coordinated and successful action in times of crisis (Leana and van Buren 1999; Faraj and Sproull 2000; Gittell et al. 2006; McGuinness and Johnson 2014). Similarly, it is argued that relationships of shared goals, shared knowledge, and mutual respect lead to high levels of coordination and positive performance effects (Gittell 2001, 2002; Gittell et al. 2000). A shared vision among the organization's members can also help to successfully implement a solution, especially during a crisis (Weick 1993; Weick et al. 1999; Horne and Orr 1998). Based on social capital and positive relationships, "organizations can tap into their networks when responding to adverse events for needed insight and assistance" (Sutcliffe and Vogus 2003, p. 105). Empirical evidence could be found for the relationship between relational reserves and recovery (Gittell et al. 2006), relational coordination and resilient response (Gittell 2008) as well as social capital resources and the resilience of family firms (Brewton et al. 2010; Danes et al. 2009). Social resources may be achieved through supportive mental processes that have been discussed as situated cognition (Suchman 1987), distributed cognition (Hutchins 1995), or joint cognitive systems (Hollnagel and Woods 2005). In this context, Weick (1993) points to the importance of virtual role systems in which each member cognitively 
reproduces the organization. Lengnick-Hall et al. (2011) argue that social resources result from respectful interactions [that means face-to-face dialogues rooted in trust, honesty, and self-respect (Weick 1993)]. Comfort (1999) proposes that it can be helpful to connect members' perceptions through enhanced communication and imaging technology. Finally, researchers call for an open, trustful, and learningoriented organizational culture (see, e.g., Teixeira and Werther 2013; Mafabi et al. 2015; Pal et al. 2014; Sawalha 2015).

Proposition 3 Social resources positively influence the resilience of organizations. Specifically, those resources foster the development of coping capabilities.

\subsubsection{Power and responsibility}

Crises can open "windows of opportunity" for adaptation processes (see, e.g., Tyre and Orlikowski 1994). However, crises alone do not automatically lead to learning and overall change. Organizations often generate new knowledge ("lessons learned"), but fail to translate this knowledge into new behaviors. In this context, power and responsibility play an important role.

From the innovation and learning literature, we know that cognitive processes, learning, and capabilities in organizations are associated with power relationships (e.g., Contu and Willmott 2003; Todorova and Durisin 2007; Vince 2001). With the endeavor to achieve their goals, powerful actors can foster as well we hinder organizational learning or change processes. In particular, they have an impact on the use of new knowledge and solutions via resource allocation processes (Todorova and Durisin 2007). For example, Dougherty and Hardy (1996) could show that the inability to connect new products with organizational resources results from rigidity of power structures. Thus, power relationships can explain why some new knowledge is used for change, while other knowledge is not; and why some organizations are better able to use new knowledge than others. As it is nearly impossible to learn when power relationships impede or deny this process (Contu and Willmott 2003), organizations should be aware of their power relationships and trigger changes if necessary. One of the most important principals in fostering organizational resilience is power based on expertise and experience rather than hierarchical position (Lengnick-Hall et al. 2011; Sutcliffe and Vogus 2003; Weick et al. 1999).

Researchers agree that resilient organizations are not managed hierarchically. Rather, those organizations rely on decentralization, self-organization, and shared decision-making (Mallak 1998; Denhardt and Denhardt 2010; Lengnick-Hall et al. 2011). This can be explained by the need for flexibility and adaptation in complex, dynamic, and uncertain environments. While mechanistic structures can amplify the impact of disasters, organic structures can mitigate them and contribute to improving resilience (e.g., Jaaron and Backhouse 2014). Thus, it seems to be useful if "each organization member has both the discretion and the responsibility for ensuring attainment of organizational interests" (Lengnick-Hall et al. 2011, p. 247). If all organization members feel that they can move something and that they are responsible for the organization's development, they are more likely open to 
change. Then they are willing to act as a sensor for change, point to inappropriate behaviors, and find new solutions (Cheese 2016). Against this background, the degree of involvement and empowerment of employees through to lower levels of the organization is becoming increasingly important (Cheese 2016; McManus et al. 2008; Lampel et al. 2014). For example, it could be shown that employee stock ownership in combination with employee involvement in strategic decision-making improves organizational resilience (Lampel et al. 2014).

Proposition 4 Power based on expertise and shared responsibilities positively influence the resilience of organizations. Specifically, they foster the development of adaptation capabilities.

\section{Conclusion and implications for future research}

Our review suggests that resilience is a fundamental organizational ability that is directed toward organizational advancement. It enables firms to withstand stresses, continuously innovate, and quickly adapt to changes. Consequently, resilience may be an important source of sustainable competitive advantage and should be developed deliberately. However, more knowledge is needed about how organizational resilience works and how it can be developed. Most empirical studies investigated organizational resilience-or the absence thereof-by retrospective analyses after a threatening situation (Linnenluecke and Griffiths 2012). They are descriptive and outcome-focused (Lengnick-Hall et al. 2011). More insight can be gained by looking at the underlying mechanisms that foster the development of organizational resilience. For this reason, we developed a conceptual framework that combines two promising approaches in resilience research: a processual approach and a focus on resilience capabilities. This framework defines three successive resilience stages (anticipation, coping, and adaptation) and illustrates resilience capabilities that underlie these stages. We used a broad range of literature to describe the different resilience stages, the role of single capabilities, and their interactions. It could be shown that only a combination of capabilities of all three stages can lead to resilient organizations. Organizations must possess proactive capabilities (resilience potential) and reactive capabilities (resilience realization). Furthermore, they must possess cognitive as well as behavioral resilience capabilities. Our conceptualization also points to main antecedents and drivers of organizational resilience (capabilities). We highlight a firm's prior knowledge base as main antecedent and resource availability, social resources, and power and responsibility as main drivers/sources of resilience.

To capture the highly complex, socially embedded, and path-dependent resilience capabilities, future research should apply new research designs that are less retrospective and more ethnographical. For example, researchers might use observational methods or conversation analysis to study how organizations respond to developments in their environments and how they manage their competitive advantages in the face of crisis (Teixeira and Werther 2013). Future studies might focus on concrete practices that are performed during a crisis, how they evolve over 
time, and how these practices interact with each other. Furthermore, they could complement and expand our findings on antecedents and drivers of resilience. It is particularly important to study their interactions and interdependencies as well as to highlight the role of different contexts. Based on this knowledge, researchers might also develop questionnaires to capture resilience capabilities as well as resilience factors quantitatively and prove for statistical correlations. Such research might build a stronger theoretical foundation of organizational resilience. It may also provide important insights into an effective management of resilience in practice.

Undoubtedly, our conceptualization has shown that we can learn much from other disciplines. There is little information on resilience capabilities in organization and management studies, but the research in other disciplines (e.g., psychology, ecology, and resilience engineering) is very insightful. Therefore, management researchers should also pay attention to other research fields and include existing ideas and findings in their work. While we know much about organizational coping with unexpected events, we know less about the anticipation and learning processes and the interaction of the three resilience stages. To close these research gaps, future studies can build on our framework and focus on less-explored parts of the resilience process. For example, researchers may investigate how organizations actually prepare for unexpected events, accept problems, and learn from them. Future research should also provide more insight into the determinants of the resilience process. For example, future studies might clarify the essential role of organizational knowledge, structure, and culture in the development of an organization's ability to deal with unexpected and threatening situations. It also seems useful to differentiate between different levels of analysis, e.g., determinants on the individual, group, and organizational levels.

Open Access This article is distributed under the terms of the Creative Commons Attribution 4.0 International License (http://creativecommons.org/licenses/by/4.0/), which permits unrestricted use, distribution, and reproduction in any medium, provided you give appropriate credit to the original author(s) and the source, provide a link to the Creative Commons license, and indicate if changes were made.

\section{References}

Aguilar, Francis J. 1967. Scanning the business environment. New York: Macmillan.

Aldrich, Howard E. 1999. Organizations evolving. Newbury Park: Sage.

Alesi, Patrick. 2008. Building enterprise-wide resilience by integrating business continuity capability into day-to-day business culture and technology. Journal of Business Continuity \& Emergency Planning 2: 214-220.

Alliger, George M., Christopher P. Cerasoli, Scott I. Tannenbaum, and William B. Vessey. 2015. Team resilience: How teams flourish under pressure. Organizational Dynamics 44: 176-184.

Ansoff, Harry I. 1975. Managing strategic surprise by response to weak signals. California Management Review 18: 21-33.

Ates, Aylin, and Umit Bititci. 2011. Change process: A key enabler for building resilient SMEs. International Journal of Production Research 49: 5601-5618.

Baum, Joel.A.C., and Kristina B. Dahlin. 2007. Aspiration performance and railroads' patterns of learning from train wrecks and crashes. Organization Science 18: 368-385.

Bechky, Beth A., and Gerardo Okhuysen. 2011. Expecting the unexpected? How SWAT officers and film crews handle surprises. Academy of Management Journal 54: 239-261. 
Beinhocker, Eric D. 1999. Robust adaptive strategies. MIT Sloan Management Review 40: 95-106.

Bhamra, Ran, Samir Dani, and Kevin Burnard. 2011. Resilience: the concept, a literature review and future directions. International Journal of Production Research 49: 5375-5393.

Boin, Arjen, and Allan McConnell. 2007. Preparing for critical infrastructure breakdowns: the limits of crisis management and the need for resilience. Journal of Contingencies and Crisis Management 15 : 50-59.

Boin, Arjen, and Michel J.G. van Eeten. 2013. The Resilient Organization-A critical appraisal. Public Management Review 15: 429-445.

Boin, Arjen, Paul't Hart, Eric Stern, and Bengt Sundelius. 2005. The politics of crisis management: Public leadership under pressure. Cambridge: Cambridge University Press.

Bourgeois III, L.Jay. 1981. On the measurement of organizational slack. Academy of Management Review 6: 29-39.

Bourrier, Mathilde. 1996. Organizing maintenance work at two nuclear power plants. Journal of Contingencies and Crisis Management 4: 104-112.

Brewton, Katherine E., Sharon M. Danes, Kathryn Stafford, and George W. Haynes. 2010. Determinants of rural and urban family firm resilience. Journal of Family Business Strategy 1: 155-166.

Burke, Ronald J. 2005. Effects of 9/11 on individuals and organizations: down but not out! Disaster Prevention and Management: An International Journal 14: 629-638.

Burnard, Kevin, and Ran Bhamra. 2011. Organisational resilience: development of a conceptual framework for organisational responses. International Journal of Production Research 49: 5581-5599.

Carley, Kathleen M. 1991. Designing organizational structures to cope with communication breakdowns: a simulation model. Industrial Crisis Quarterly 5: 19-57.

Carley, Kathleen M., and John R. Harrald. 1997. Organizational learning under fire: Theory and practice. American Behavioral Scientist 40: 310-332.

Carmeli, Abraham, and Gideon D. Markman. 2011. Capture, governance, and resilience: strategy implications from the history of Rome. Strategic Management Journal 32: 322-341.

Catalan, Catherine, and Benoit Robert. 2011. Evaluation of organizational resilience: application in Quebec. Montréal: Centre Risque \& Performance, École Polytechnique de Montréal.

Catino, Maurizio. 2008. A review of literature: Individual blame vs. organizational function logics in accident analysis. Journal of Contingencies and Crisis Management 16: 53-62.

Cheese, Peter. 2016. Managing risk and building resilient organisations in a riskier world. Journal of Organizational Effectiveness: People and Performance 3: 323-331.

Christianson, Marlys K., Maria T. Farkas, Kathleen M. Sutcliffe, and Karl E. Weick. 2009. Learning through rare events: Significiant interruptions at the Baltimore and Ohio Railroad Museum. Organization Science 20: 846-860.

Cohen, Wesley M., and Daniel A. Levinthal. 1990. Absorptive capacity: A new perspective on learning and innovation. Administrative Science Quarterly 35: 128-152.

Comfort, Louise K. 1999. Shared Risk: Complex Systems in Seismic Response. New York: Pergamon.

Contu, Alessia, and Hugh Willmott. 2003. Re-embedding situatedness: The importance of power relations in learning theory. Organization Science 14: 283-296.

Coutu, Diane L. 2002. How resilience works. Harvard Business Review 80: 46-55.

Crichton, Margarete T., Cameron G. Ramsay, and Terence Kelly. 2009. Enhancing organizational resilience through emergency planning: Learnings from cross-sectorial lessons. Journal of Contingencies and Crisis Management 17: 24-37.

Cyert, Richard M., and James G. March. 1963. A behavioral theory of the firm. New Jersey: Prentice-Hall.

Danes, Sharon M., Jinhee Lee, Sayali Amarapurkar, Kathryn Stafford, George W. Haynes, and Katherine E. Brewton. 2009. Determinants of family business resilience after a natural disaster by gender of business owner. Journal of Developmental Entrepreneurship 14: 333-354.

Daudelin, Marilyn W. 1997. Learning from experience through reflection. Organizational Dynamics 24: $36-48$.

Day, George S., and Paul J.H. Schoemaker. 2005. Scanning the periphery. Harvard Business Review 83: $135-148$.

Dayton, Bruce W. ed. 2004. Managing Crises in the Twenty-First Century. International Studies Review 6: $165-194$.

De Carvalho, Antonio Oliveira, Ivano Ribeiro, Claudia Brito Silva Cirani, and Renato Fabiano Cintra. 2016. Organizational resilience: A comparative study between innovative and non-innovative 
companies based on the financial performance analysis. International Journal of Innovation 4: 58-69.

Demmer, William A., Shawnee K. Vickery, and Roger Calantone. 2011. Engendering resilience in smalland medium-sized enterprises (SMEs): A case study of Demmer Corporation. International Journal of Production Research 49: 5395-5413.

Denhardt, Janet, and Robert Denhardt. 2010. Building organizational resilience and adaptive management. In Handbook of adult resilience, ed. John W. Reich, Alex J. Zautra, and John Stuart Hall, 333-349. New York: The Guilford Press.

Dougherty, Deborah, and Cythia Hardy. 1996. Sustained product innovation in large, mature organizations: Overcoming innovation-to-organization problems. Academy of Management Journal 39: 1120-1153.

Drabek, Thomas E., and David A. McEntire. 2003. Emergent phenomena and the sociology of disaster: lessons, trends and opportunities from the research literature. Disaster Prevention and Management An International Journal 12: 97-112.

Duit, Andreas. 2016. Resilience thinking: Lessons for Public Administration. Public Administration 94: 364-380.

Edmondson, Amy C. 1999. Psychological safety and learning behavior in work teams. Administrative Science Quarterly 44: 350-383.

Edmondson, Amy C. 2002. The local and variegated nature of learning in organizations: A group-level perspective. Organization Science 13: 128-146.

Elliott, Dominic, Ethné Swartz, and Brahim Herbane. 1999. Just waiting for the next big bang: Business continuity planning in the UK finance sector. Journal of Applied Management Studies 8: 43-60.

Elliott, Dominic, Ethné Swartz, and Brahim Herbane. 2002. Business continuity management-a crisis management approach. London: Routledge.

Ely, Robin J., and Laura M. Roberts. 2008. Shifting frames in team-diversity research: From difference to relationships. In Diversity at work, ed. Arthur P. Brief, 175-202. Cambridge: Cambridge University Press.

Faraj, Samer, and Lee Sproull. 2000. Coordinating expertise in software development teams. Management Science 46: 1554-1568.

Faraj, Samer, and Yan Xiao. 2006. Coordination in fast-response organizations. Management Science 52: 1155-1169.

Feldman, Martha S. 2003. A performative perspective on stability and change in organizational routines. Industrial and Corporate Change 12: 727-752.

Ferreira, Pedro N.P., John R. Wilson, Brandon Ryan, and Sarah Sharples. 2011. Measuring resilience in the planning of rail engineering work. In Resilience engineering in practice: A guidebook, ed. Erik Hollnagel, Jean Pariés, David D. Woods, and John Wreathall, 145-156. Aldershot: Ashgate.

Fiol, C. Marlene, and Marjorie A. Lyles. 1985. Organizational learning. Academy of Management Review 10: 803-813.

Hamel, Gary, and Liisa Vaelikangas. 2003. The quest for resilience. Harvard Business Review 81: 52-65.

Gherardi, Silvia. 2006. Organizational knowledge: The texture of workplace learning. Oxford: Blackwell Publishers.

Gibb, Forbes, and Steven Buchanan. 2006. A framework for business continuity management. International Journal of Information Management 26: 128-141.

Gittell, Jody H. 2001. Supervisory span, relational coordination and flight departure performance: A reassessment of post-bureaucracy theory. Organization Science 12: 467-482.

Gittell, Jody H. 2002. Coordinating mechanisms in care provider groups: Relational coordination as a mediator and input uncertainty as a moderator of performance effects. Management Science 48: $1408-1426$.

Gittell, Jody H. 2008. Relationships and resilience: Care provider responses to pressures from managed care. The Journal of Applied Behavioral Science 44: 25-47.

Gittell, Jody H., Kathleen M. Fairfield, Benjamin Bierbaum, William Head, Robert Jackson, Michael Kelly, Richard Laskin, et al. 2000. Impact of relational coordination on quality of care, postoperative pain and functioning, and the length of stay: A ninehospital study of surgical patients. Medical Care 38: 807-819.

Gittell, Jody H., Kim Cameron, Sandy Lim, and Victor Rivas. 2006. Relationships, layoffs, and organizational resilience airline industry responses to September 11. The Journal of Applied Behavioral Science 42: 300-329. 
Golden, William, and Philip Powell. 2000. Towards a definition of flexibility: In search of the Holy Grail? Omega 28: 373-384.

Gomes, José O., Marcos R. Borges, Gilbert J. Huber, and Paul V.R. Carvalho. 2014. Analysis of the resilience of team performance during a nuclear emergency response exercise. Applied Ergonomics 45: 780-788.

Gressgård, Leif J., and Kare Hansen. 2015. Knowledge exchange and learning from failures in distributed environments: The role of contractor relationship management and work characteristics. Reliability Engineering and System Safety 133: 167-175.

Haunschild, Pamela R., and Bilian Ni Sullivan. 2002. Learning from complexity: Effects of prior accidents and incidents on airlines' learning. Administrative Science Quarterly 47: 609-643.

Helfat, Constance E. 1994. Evolutionary trajectories in petroleum firm R\&D. Management Science 40: 1720-1747.

Herbane, Brahim. 2010. Small business research: Time for a crisis-based view. International Small Business Journal 28: 43-64.

Herbane, Brahim, Dominic Elliot, and Ethné Swartz. 2004. Business continuity management: time for a strategic role? Long Range Planning 37: 435-457.

Hermann, Charles F. 1963. Some consequences of crisis which limit the viability of organisations. Administrative Science Quarterly 12: 61-82.

Hillmann, Julia, Stephanie Duchek, Julian Meyr, and Edeltraud Guenther. 2018. Educating Future Managers for Developing Resilient Organizations: The Role of Scenario Planning. Journal of Management Education 42: 461-495.

Hiltunen, Elina. 2008. Good Sources of Weak Signals: A Global Study of Where Futurists Look For Weak Signals. Journal of Futures Studies 12: 21-44.

Hirsch, Paul M., and Daniel Z. Levin. 1999. Umbrella advocates versus validity police: A life-cycle model. Organization Science 10: 199-212.

Hollnagel, Erik, and David D. Woods. 2005. Joint cognitive systems: Foundations of cognitive systems engineering. Boca Raton: CRC Press.

Horne, John F. 1997. The coming of age of organizational resilience. Business Forum 22: 24-28.

Horne, John F., and John E. Orr. 1998. Assessing Behaviors that Create Resilient Organizations. Employment Relations Today 24: 29-39.

Howard-Grenville, Jennifer A. 2005. The persistence of flexible organizational routines: The role of agency and organizational context. Organization Science 16: 618-636.

Hutchins, Edwin. 1995. Cognition in the wild. Cambridge: MIT Press.

Ilmola, Leena, and Osmo Kuusi. 2006. Filters of weak signals hinder foresight: Monitoring weak signals efficiently in corporate decision-making. Futures 38: 908-924.

Ingram, Paul, and Joel A.C. Baum. 1997. Opportunity and constraint: Organizations' learning from the operating and competitive experience of industries. Strategic Management Journal 18: 75-98.

Ismail, Hossam S., Jenny Poolton, and Hossein Sharifi. 2011. The role of agile strategic capabilities in achieving resilience in manufacturing-based small companies. International Journal of Production Research 49: 5469-5487.

Jaaron, Ayham A.M., and Chris J. Backhouse. 2014. Service organisations resilience through the application of the vanguard method of systems thinking: a case study approach. International Journal of Production Research 52: 2026-2041.

Jabareen, Yosef. 2009. Building a conceptual framework: philosophy, definitions, and procedure. International Journal of Qualitative Methods 8: 49-62.

James, Erika H., and Lynn P. Wooten. 2005. Leadership as (un)usual: how to display competence in times of crisis. Organizational Dynamics 34: 141-152.

Janis, Irving L. 1982. Groupthink: Psychological studies of policy decisions and fiascoes. Boston: Houghton Mifflin.

Jaques, Tony. 2007. Issue management and crisis management: An integrated, non-linear, relational construct. Public Relations Review 33: 147-157.

Jones, Oswald. 2006. Developing absorptive capacity in mature organizations: The change agent's role. Management Learning 37: 355-376.

Kantur, D., and A. İşeri-Say. 2012. Organizational resilience: A conceptual integrative framework. Journal of Management and Organization 18: 762-773.

Kendra, James M., and Tricia Wachtendorf. 2003. Elements of Resilience after the World Trade Center Disaster: Reconstituting New York City’s Emergency Operations Center. Disasters 27: 7-53. 
Kim, Ji-Yub Jay, and Anne S. Miner. 2007. Vicarious learning from the failures and near-failures of others: Evidence from the US commercial banking industry. Academy of Management Journal 50: 687-714.

Kirchsteiger, Christian. 1999. Status and functioning of the European Commission's major accident reporting system. Journal of Hazardous Materials 65: 211-231.

Kitano, Hiroaki. 2004. Biological robustness. Nature Reviews Genetics 5: 826-837.

Lampel, Joseph, and Zur Shapira. 2001. Judgmental errors, interactive norms, and the difficulty of detecting strategic surprises. Organization Science 12: 599-611.

Lampel, Joseph, Jamal Shamsie, and Zur Shapira. 2009. Experiencing the improbable: Rare events and organizational learning. Organization Science 20: 835-845.

Lampel, Joseph, Ajay Bhalla, and Pushkar P. Jha. 2014. Does governance confer organisational resilience? Evidence from UK employee owned businesses. European Management Journal 32: 66-72.

Leana, Carry R., and Harry J. van Buren III. 1999. Organizational social capital and employment practices. Academy of Management Review 24: 538-555.

Lengnick-Hall, Cynthia A., and Tammy E. Beck. 2005. Adaptive fit versus robust transformation: How organizations respond to environmental change. Journal of Management 31: 738-757.

Lengnick-Hall, Cynthia A., and Tammy E. Beck. 2009. Resilience capacity and strategic agility: Prerequisites for thriving in a dynamic environment. In Resilience engineering perspectives, Volume 2. Preparation and restoration, ed. Christopher P. Nemeth, Erik Hollnagel, and Sidney Dekker, 39-70. Aldershot: Ashgate Publishing.

Lengnick-Hall, Cynthia A., Tammy E. Beck, and Mark L. Lengnick-Hall. 2011. Developing a capacity for organizational resilience through strategic human resource management. Human Resource Management Review 21: 243-255.

Lewin, Arie Y., Silvia Massini, and Carine Peeters. 2011. Micro-foundations of internal and external practiced routines of absorptive capacity. Organization Science 22: 81-98.

Limnios, Elena A.M., Tim Mazzarol, Anas Ghadouani, and Steven G.M. Schilizzi. 2014. The resilience architecture framework: four organizational archetypes. European Management Journal 32: 104-116.

Lindberg, Anna K., Sven O. Hansson, and Carl Rollenhagen. 2010. Learning from accidents-what more do we need to know? Safety Science 48: 714-721.

Linnenluecke, Martina K. 2017. Resilience in business and management research: A review of influential publications and a research agenda. International Journal of Management Reviews 19: 4-30.

Linnenluecke, Martina K., and Andrew Griffiths. 2010. Beyond adaptation: resilience for business in light of climate change and weather extremes. Business and Society 49: 477-511.

Linnenluecke, Martina K., and Andrew Griffiths. 2012. Assessing organizational resilience to climate and weather extremes: complexities and methodological pathways. Climate Change 113: 933-947.

Linnenluecke, Martina K., Andrew Griffiths, and Monika Winn. 2012. Extreme weather events and the critical importance of anticipatory adaptation and organizational resilience in responding to impacts. Business Strategy and the Environment 21: 17-32.

Lorsch, Jay W. 1986. Managing Culture: The Invisible Barrier to Strategic Change. California Management Review 28: 95-109.

Lynham, Susan A. 2002. The general method of theory-building research in applied disciplines. Advances in Developing Human Resources 4: 221-241.

Madni, Azad M., and Scott Jackson. 2009. Towards a conceptual framework for resilience engineering. IEEE Systems Journal 3: 181-191.

Madsen, Peter M. 2009. These lives will not be lost in vain: Organizational learning from disaster in U.S. coal mining. Organization Science 20: 861-875.

Mafabi, Samuel, John C. Munene, and Augustine Ahiauzu. 2015. Creative climate and organisational resilience: the mediating role of innovation. International Journal of Organizational Analysis 23: 564-587.

Maitlis, Sally. 2005. The social processes of organizational sensemaking. Academy of Management Journal 48: 21-49.

Maitlis, Sally, and Marlys Christianson. 2014. Sensemaking in organizations: Taking stock and moving forward. The Academy of Management Annals 8: 57-125.

Majchrzak, Ann, Sirkka L. Jarvenpaa, and Andrea B. Hollingshead. 2007. Coordinating expertise among emergent groups responding to disasters. Organization Science 18: 147-161. 
Mallak, Larry A. 1998. Measuring resilience in health care provider organizations. Health Manpower Management 24: 148-152.

March, James G., and Herbert A. Simon. 1958. Organizations. New York: Wiley.

Marcus, Alfred A., and Mary L. Nichols. 1999. On the edge: Heeding the warnings of unusual events. Organization Science 10: 482-499.

McCann, Joseph. 2004. Organizational effectiveness: Changing concepts for changing environments. Human Resource Planning 27: 42-50.

McGuinness, Martina, and Noel Johnson. 2014. Exploiting social capital and path-dependent resources for organisational resilience: Preliminary findings from a study on flooding. Procedia Economics and Finance 18: 447-455.

McManus, Sonia, Erica Seville, John Vargo, and David Brunsdon. 2008. A facilitated process for improving organizational resilience. Natural Hazards Review 9: 81-90.

Meredith, Jack. 1993. Theory building through conceptual methods. International Journal of Operations and Production Management 13: 3-11.

Miller, Danny, and Peter H. Friesen. 1980. Momentum and revolution in organizational adaptation. Academy of Management Journal 23: 591-614.

Nelson, Richard R., and Sidney G. Winter. 1982. An evolutionary theory of economic change. Cambridge: Harvard University Press.

Nicolini, Davide, Silvia Gherardi, and Dvora Yanow. ed. 2003. Knowing in organizations: a practicebased approach. Armonk: M. E. Sharpe.

Ortiz-de-Mandojana, Natalia, and Pratima Bansal. 2016. The long-term benefits of organizational resilience through sustainable business practices. Strategic Management Journal 37: 1615-1631.

Pal, Rudrajeet, Håkan Torstensson, and Heikki Mattila. 2014. Antecedents of organizational resilience in economic crises - an empirical study of Swedish textile and clothing SMEs. International Journal of Production Economics 147: 410-428.

Patriotta, Gerardo. 2003. Sensemaking on the shop floor: Narratives of knowledge in organizations. Journal of Management Studies 40: 349-375.

Pearson, Christine M., and Judith A. Clair. 1998. Reframing crisis management. Academy of Management Review 23: 59-76.

Pentland, Brian T., and Martha S. Feldman. 2008. Designing routines: On the folly of designing artifacts, while hoping for patterns of action. Information and Organization 18: 235-250.

Piderit, Sandy Kristin. 2000. Rethinking resistance and recognizing ambivalence: A multidimensional view of attitudes toward an organizational change. Academy of Management Review 25: 783-794.

Powley, Edward H. 2009. Reclaiming resilience and safety: Resilience activation in the critical period of crisis. Human Relations 62: 1289-1326.

Pregenzer, Arian L. 2014. Evolution and resilience of the nuclear nonproliferation regime. AIP Conference Proceedings Nuclear Weapon Issues in the 21st Century 1596: 152-159.

Randeree, Kasim, Ashish Mahal, and Anjli Narwani. 2012. A business continuity management maturity model for the UAE banking sector. Business Process Management Journal 18: 472-492.

Reilly, Anne H. 1993. Preparing for the worst: the process of effective crisis management. Organization and Environment 7: 115-143.

Reinmoeller, Patrick, and Nicole van Baardwijk. 2005. The link between diversity and resilience. MIT Sloan Management Review 46: 61-65.

Rerup, Claus. 2001. Houston, we have a problem: Anticipation and improvisation as sources of organizational resilience. Comportamento Organizacional E Gestao 7: 27-44.

Rerup, Claus. 2009. Attentional triangulation: Learning from unexpected rare crises. Organization Science 20: 876-893.

Robb, Dean. 2000. Building resilient organizations. OD Practitioner 32: 27-32.

Robert, Benoît. 2010. Organizational Resilience-Concepts and evaluation Method. Montréal: Presse de l'École Polytechnique de Montréal.

Roberts, Karlene H., and Robert Bea. 2001. Must accidents happen? Lessons from high-reliability organizations. The Academy of Management Executive 15: 70-78.

Roberts, Karlene H., Peter M. Madsen, and Vinit M. Desait. 2005. The space between in space transportation: A relational analysis of the failure of STS-107. In Organization at the limit-NASA and the Columbia Disaster, ed. William H. Starbuck and Moshe Farjoun, 81-98. Oxford: Blackwell.

Rochlin, Gene I. 1989. Informal Organisational Networking as a Crisis Avoidance Strategy: US Naval Flight Operations as a Case Study. Industrial Crisis Quarterly 3: 159-176. 
Rochlin, Gene I., Todd R. LaPorte, and Karlene H. Roberts. 1987. The self-designing high reliability organization: Aircraft carrier flight operation at sea. Naval War College Review 40: 76-90.

Ron, Neta, Raanan Lipshitz, and Micha Popper. 2006. How organizations learn: Post-flight reviews in an F-16 fighter squadron. Organization Studies 27: 1069-1089.

Rosenkopf, Lori, and Atul Nerkar. 2001. Beyond local search: Boundary-spanning, exploration, and impact in the optical disk industry. Strategic Management Journal 22: 287-306.

Ryle, Gilbert. 1979. On thinking. Oxford: Blackwell.

Sagan, Scott D. 1993. The limits of safety: Organizations, accidents and nuclear weapons. Princeton: Princeton University Press.

Sawalha, Ihab Hanna Salman. 2015. Managing adversity: understanding some dimensions of organizational resilience. Management Research Review 38: 346-366.

Schulman, Paul R. 2004. General attributes of safe organizations. Quality and Safety In Health Care 13: ii39-ii44.

Schultze, Ulrike, and Wanda J. Orlikowski. 2004. A practice perspective on technology-mediated network relations: The Use of Internet-based self-serve technologies. Information System Research 15: 87-106.

Seville, Erica, David Brunsdon, Andre Dantas, Jason Le Masurier, Suzanne Wilkinson, and John Vargo. 2008. Organisational resilience: Researching the reality of New Zealand organisations. Journal of Business Continuity and Emergency Planning 2: 258-266.

Sheffi, Yossi. 2007. The resilient enterprise: overcoming vulnerability for competitive advantage. Cambridge: MIT Press.

Sirkin, H.L., P. Keenan, and A. Jackson. 2005. The hard side of change management. Harvard Business Review 83: 109-118.

Smart, C., and I. Vertinsky. 1977. Designs for crisis decision units. Administrative Science Quarterly 22: 640-657.

Smart, Carolyne, and Ilan Vertinsky. 1984. Strategy and the environment: A study of corporate responses to crises. Strategic Management Journal 5: 199-213.

Smith, Denis, and Dominic Elliott. 2007. Exploring the barriers to learning from crisis -Organizational learning and crisis. Management Learning 38: 519-538.

Somers, Scott. 2009. Measuring resilience potential: An adaptive strategy for organizational crisis planning. Journal of Contingencies and Crisis Management 17: 12-23.

Sørensen, Jesper B. 2002. The strength of corporate culture and the reliability of firm performance. Administrative Science Quarterly 47: 70-91.

Starbuck, William H. 2009. Cognitive reactions to rare events: Perceptions, uncertainty, and learning. Organization Science 20: 925-937.

Stead, Eleanor, and Clive Smallman. 1999. Understanding business failure: learning and un-learning from industrial crises. Journal of Contingencies and Crisis Management 7: 1-18.

Stuart, Toby E., and Joel M. Podolny. 1996. Local search and the evolution of technological capabilities. Strategic Management Journal 17: 21-28.

Suchman, Lucy A. 1987. Plans and situated actions: the problem of human-machine communication. Cambridge: Cambridge University Press.

Sutcliffe, Kathleen M., and Timothy J. Vogus. 2003. Organizing for resilience. In Positive organizational scholarship: Foundations of a new discipline, ed. Kim Cameron, Jane E. Dutton, and Robert E. Quinn, 94-110. San Francisco: Berrett-Kehler.

Teece, David J., Gary Pisano, and Amy Shuen. 1997. Dynamic capabilities and strategic management. Strategic Management Journal 18: 509-533.

Teixeira, Eduardo de Oliveira, and William B. Werther Jr. 2013. Resilience: Continuous renewal of competitive advantages. Business Horizons 56: 333-342.

Teoh, Say Yen, and Hossein S. Zadeh. 2013. Strategic resilience management model: Complex enterprise systems upgrade implementation. PACIS 2013 Proceedings: Paper 242.

Tierney, Kathleen J. 2003. Conceptualizing and measuring organizational and community resilience: Lessons from the emergency response following the September 11, 2001 attack on the World Trade Center. Disaster Research Center, Preliminary Papers 329.

Todorova, Gergana, and Boris Durisin. 2007. Absorptive capacity: Valuing a reconceptualization. Academy of Management Review 32: 774-786.

Toft, Brian, and Simon Reynolds. 1994. Learning from disasters: A management approach. Newton: Butterworth-Heinemann. 
Turner, Barry A. 1976. The organizational and interorganizational development of disasters. Administrative Science Quarterly 21: 378-397.

Tyre, Marcie J., and Wanda J. Orlikowski. 1994. Windows of opportunity: Temporal patterns of technological adaptation in organizations. Organization Science 5: 98-118.

Uskali, Turo. 2005. Paying attention to weak signals: The key concept for innovation journalism. Innovation Journalism 2: 33-49.

Vaelikangas, Liisa, and A. Georges L. Romme. 2013. How to design for strategic resilience: A case study in retailing. Journal of Organization Design 2: 44-53.

Vastveit, Kirsti R., Arjen Boin, and Ove Njå. 2015. Learning from incidents: Practices at a Scandinavian refinery. Safety Science 79: 80-87.

Vaughan, Diane. 2005. System effects: On slippery slopes, repeating negative patterns, and learning from mistake? In Organization at the limit-NASA and the Columbia Disaster, ed. William H. Starbuck and Moshe Farjoun, 41-59. Oxford: Blackwell.

Vince, Russ. 2001. Power and emotion in organizational learning. Human Relations 54: 1325-1351.

Visser, Max. 2007. Deutero-learning in organizations: A review and a reformulation. Academy of Management Review 32: 659-667.

Vogus, Timothy J., and Kathleen M. Sutcliffe. 2007. Organizational resilience: Towards a theory and research agenda. IEEE Systems, Man, and Cybernetics 2007 Proceedings 2007: 3418-3422.

Weber, Rosina, David W. Aha, and Irma Becerra-Fernandez. 2001. Intelligent lessons learned systems. Expert Systems with Applications 20: 17-34.

Weick, Karl E. 1969. The social psychology of organizing. Reading: Addison-Wesley.

Weick, Karl E. 1988. Enacted sensemaking in crisis situations. Journal of Management Studies 25: 305-317.

Weick, Karl E. 1993. The collapse of sensemaking in organizations: The Mann Gulch disaster. Administrative Science Quarterly 38: 628-652.

Weick, Karl E., and Karlene H. Roberts. 1993. Collective mind in organizations: Heedful interrelating on flight decks. Administrative Science Quarterly 38: 357-381.

Weick, Karl E., Kathhleen M. Sutcliffe, and David Obstfeld. 1999. Organizing for high reliability: Processes of collective mindfulness. In Research in organizational behavior, ed. Barry M. Staw and Robert I. Sutton, 81-123. Greenwich: Jai Press.

Weick, Karl E., Kathleen M. Sutcliffe, and David Obstfeld. 2005. Organizing and the process of sensemaking. Organization Science 16: 409-421.

Westrum, Ron. 1988. Organizational and inter-organizational thought. Paper presented at the World Bank Conference on Safety Control and Risk Management.

Wildavsky, Aaron B. 1991. Searching for Safety. New Brunswick: Transaction.

Williams, Trenton.A., Daniel A. Gruber, Kathleen M. Sutcliffe, Dean A. Shepherd, and Eric Yanfei Zhao. 2017. Organizational response to adversity: fusing crisis management and resilience research streams. Academy of Management Annals 11: 733-769.

Publisher's note Springer Nature remains neutral with regard to jurisdictional claims in published maps and institutional affiliations. 